\title{
Editorial
}

\section{Un puente entre el médico y el paciente}

B. Muñoz

Responsable de la Sección de Nutrición del Suplemento "A tu salud" de La Razón

Publicado en Internet:

4-abril-2014

Beatriz Muñoz:

bmunoz@larazon.es

Ya lo decía Ortega y Gasset: "El periodista es aquel que escribe de todo sin saber de nada". Con afirmaciones como esta, la especialización en Periodismo se convierte casi en una obligación. Dentro de las diferentes áreas que dan forma al conocimiento informativo, divulgar información científica supone, en muchos casos, una ardua tarea por el desafío de traducir la complejidad de campos como la Medicina a un lenguaje comprensible y atractivo, pero sin perder el rigor científico.

La nutrición y el cáncer se han posicionado, en los últimos años, como dos áreas de gran interés para el ciudadano. En el caso de la nutrición, hay una viva dinámica de cambios. Así, lo que hace unos años se exponía como perjudicial para el organismo, hoy pasa a ser beneficioso e, incluso, imprescindible para gozar de un buen estado de salud. Así, aceite de oliva, pescado azul o pan, entre otros, son solo algunos de los alimentos que, en la mayoría de las ocasiones, alabamos o desterramos sin ningún fundamento científico. Además, no debemos olvidar que los consumidores españoles cuentan con un conocimiento muy limitado y, en ocasiones, confuso, acerca de la información nutricional sobre los alimentos. Quizás, merezca la pena plantearse si tanta información sobre nutrición haya podido crear una saturación informativa que, en muchas ocasiones, conduce a la confusión.
En el intento de poner freno a esta situación, la Asociación Nacional de Informadores de Salud (ANIS) y la Federación de Industrias de la Alimentación y Bebidas (FIAB) presentaron, el pasado mes de octubre, el "Manifiesto por una Comunicación Responsable en Alimentación y Salud"1,2, con el que se pretende dotar de mayor rigor y objetividad a las noticias e informaciones que se publican en este ámbito, ante la preocupación de que la desinformación en nutrición pueda suponer un riesgo para la salud.

Como en cualquier otra información, en temas de alimentación y salud existen fuentes con intereses y puntos de vista distintos. Es necesario contar con fuentes relevantes, sólidas y fiables que aporten opiniones cualificadas del mayor número posible de actores. Igualmente, resulta necesario contrastar las noticias servidas por agencia sobre hallazgos o informaciones procedentes de fuera de España. Dado el carácter sensible de la información sobre alimentación y salud, la originalidad en la exposición y el enfoque no debe impedirnos mantener como premisas el rigor, el equilibrio y la precisión. Lo noticioso no puede ser solo lo negativo. Internet es una inestimable fuente de información, y a la vez se ha convertido en la principal vía de circulación de mitos y bulos sobre la alimenta- 
ción. Los informadores debemos ser objetivos respecto a las instituciones que financian una investigación sobre alimentación o nutrición, y no discriminar la difusión pública de la marca con independencia de los resultados obtenidos.

Por otra parte, los índices de supervivencia en cáncer han mejorado mucho en los últimos años gracias al incremento de la eficacia de los tratamientos y a un diagnóstico cada vez más temprano. Sin embargo, la forma de hablar de cáncer en los medios de comunicación no ha evolucionado al mismo ritmo y aún utilizamos términos y expresiones capaces de estigmatizar a aquellas personas que conviven con la enfermedad. No podemos olvidar que los informadores desempeñamos un papel fundamental en conseguir la normalización social del cáncer. En este sentido, desde el Grupo Español de Pacientes con Cáncer (GEPAC) se elaboró el decálogo del buen tratamiento informativo de la enfermedad ${ }^{3}$.

Hablar claramente y no utilizar expresiones como "larga y penosa enfermedad" es el primer paso para desestigmatizar esta patología. Expresiones como "la lucha contra el cáncer", "vencer al cáncer" o "ser valiente" tienen grandes repercusiones en los pacientes, y especialmente en los familiares de quienes no han logrado superar la enfermedad. Desde el punto de vista de los afectados, estas expresiones hacen que el cáncer se perciba como una lucha, y en las batallas generalmente gana el más fuerte o el más valiente.

Las noticias relativas a investigación en cáncer tienen siempre una gran repercusión en los pacientes. Sin embargo, es necesario dar una información muy rigurosa en cuanto a los resultados de los estudios y la eficacia de las nuevas terapias. Además, es importante mencionar si esas tera- pias están en fase de investigación y, por tanto, si aún falta mucho tiempo para que esté disponible en la práctica clínica con el fin de evitar generar falsas expectativas en los pacientes y familiares. Habitualmente se publican informaciones en las que se refleja la eficacia de terapias que no están probadas científicamente. Un mal enfoque informativo de estas cuestiones puede provocar problemas de adherencia a tratamientos convencionales en favor de terapias que no han sido contrastadas.

La información en salud ejerce, en muchas ocasiones, una labor de prevención que no debemos pasar por alto. Ser el puente entre el profesional de la salud y el paciente supone una gran responsabilidad. Y es que no debemos olvidar que una mala información también perjudica gravemente la salud de los que nos leen.

\section{BIBLIOGRAFÍA}

1. Manifiesto ANIS-FIAB: la desinformación en nutrición es un riesgo para la salud. El blog de FIAB, 30 de octubre de 2013 [en línea] [consultado el 18/02/2014]. Disponible en http://blog.fiab.es/in dex.php/manifiesto-anis-fiab-la-desinformacionen-nutricion-es-un-riesgo-para-la-salud/

2. Decálogo por una comunicación responsable en Alimentación y Salud. Pediatría basada en pruebas, 25 de noviembre de 2013 [en línea] [consultado el 18/02/2014]. Disponible en www.pediatriabasa daenpruebas.com/2013/11/decalogo-por-una-co municacion.html

3. GEPAC. Decálogo para el buen tratamiento informativo del cáncer [en línea] [consultado el 18/02/2014]. Disponible en www.gepac.es/aldia/419-gepac-presenta-un-decalogo-para-elbuen-tratamiento-informativo-del-cancer.html 